\title{
Creating long-term gridded fields of reference evapotranspiration in Alpine terrain based on a recalibrated Hargreaves method
}

\author{
Klaus Haslinger and Annett Bartsch \\ Central Institute for Meteorology and Geodynamics (ZAMG), Climate Research Department, Vienna, Austria \\ Correspondence to: Klaus Haslinger (klaus.haslinger@zamg.ac.at)
}

Received: 7 April 2015 - Published in Hydrol. Earth Syst. Sci. Discuss.: 28 May 2015

Revised: 1 March 2016 - Accepted: 2 March 2016 - Published: 21 March 2016

\begin{abstract}
A new approach for the construction of highresolution gridded fields of reference evapotranspiration for the Austrian domain on a daily time step is presented. Gridded data of minimum and maximum temperatures are used to estimate reference evapotranspiration based on the formulation of Hargreaves. The calibration constant in the Hargreaves equation is recalibrated to the Penman-Monteith equation in a monthly and station-wise assessment. This ensures, on one hand, eliminated biases of the Hargreaves approach compared to the formulation of Penman-Monteith and, on the other hand, also reduced root mean square errors and relative errors on a daily timescale. The resulting new calibration parameters are interpolated over time to a daily temporal resolution for a standard year of 365 days. The overall novelty of the approach is the use of surface elevation as the only predictor to estimate the recalibrated Hargreaves parameter in space. A third-order polynomial is fitted to the recalibrated parameters against elevation at every station which yields a statistical model for assessing these new parameters in space by using the underlying digital elevation model of the temperature fields. With these newly calibrated parameters for every day of year and every grid point, the Hargreaves method is applied to the temperature fields, yielding reference evapotranspiration for the entire grid and time period from 1961-2013. This approach is opening opportunities to create high-resolution reference evapotranspiration fields based only temperature observations, but being as close as possible to the estimates of the Penman-Monteith approach.
\end{abstract}

\section{Introduction}

The water balance in its most general form is determined by fluxes of precipitation, change in storage and evapotranspiration (Shelton, 2009). Particularly for evapotranspiration, measurement is rather costly, since it requires sophisticated techniques like eddy correlation methods or lysimeters. In hydrology, as well as agricultural sciences, the actual evapotranspiration as part of the water balance equation is mostly assessed from the potential evapotranspiration (PET). PET refers to the maximum moisture loss from the surface, determined by meteorological conditions and the surface type, assuming unlimited moisture supply (Lhomme, 1997). Since surface conditions determine the amount of PET, the concept of reference evapotranspiration (ET0) was introduced (Doorenbos and Pruitt, 1977). ET0 refers to the evapotranspiration from a standardised vegetated surface (grass) under unrestricted water supply, making ET0 independent of soil properties. Numerous methods exist for estimating ET0; differences arise in the complexity and the amount of necessary input data for calculation.

A standard method, recommended by the Food and Agricultural Organisation (FAO; Allen et al., 1998), is the Penman-Monteith (PM) formulation of ET0. There are of course countless other methods as thoroughly described in McMahon et al. (2013), but the PM equation is considered the most reliable estimate and serves as a standard for comparisons with other methods (Allen et al., 1998). PM is fully physically based and requires four meteorological parameters (air temperature, wind speed, relative humidity and net radiation). It utilises energy balance calculations at the surface to derive ET0 and is therefore considered a radiationbased method (Xu and Singh, 2000). 
On the contrary, much simpler methods which use air temperature as a proxy for radiation (Xu and Singh, 2001) are applied as alternatives for regions where the input data are not sufficient to use PM. One of these simpler methods; the method of Hargreaves (HM; Hargreaves et al., 1985), is used in this paper. It requires minimum and maximum air temperature and extra-terrestrial radiation, which can be derived from the geographical location and the day of year. Hence, HM is more broadly applicable for many regions, because temperature observations are dense and easily accessible. Nevertheless, like most temperature-based methods, HM has been developed for distinct studies and regions also representing distinct climate conditions (Xu and Singh, 2001). To avoid large errors, these temperature-based methods need to undergo a recalibration procedure to make them applicable in different climatic regions than in those they were originally designed for (Chattopadhyay and Hulme, 1997; Xu and Chen, 2005).

In this paper, the method for constructing a data set of ET0 is presented on a daily time resolution and a $1 \mathrm{~km}$ spatial resolution based on the method of Hargreaves. The HM is calibrated to the PM in a station-wise assessment. Many studies describe recalibration procedures for ET0 estimations in general (Tegos et al., 2015; Oudin et al., 2005) and for the HM in particular (Pandey et al., 2014; Tabari and Talaee, 2011; Bautista et al., 2009; Gavilán et al., 2006) in order to achieve results comparable to PM. There are also some studies describing methods for creating interpolated ET0 estimates (e. g. Aguila and Polo, 2011; Todorovic et al., 2011). However, two main methodological frameworks emerged for the interpolation of ET0 (McVicar et al., 2007): (i) interpolation of the forcing data and then calculation of ET0, or (ii) calculation of ET0 at every weather station followed by an interpolation of ET0 onto the grid. Here, we follow the first approach and combine it with methods proposed by Tegos et al. (2015) and Mancosu et al. (2014) which use spatially interpolated ET0 model parameters. Gridded data of minimum and maximum temperatures are used as forcing fields for the application of the Hargreaves formulation of ET0. The novelty of this study is the application of elevation as a predictor for the interpolation of the recalibrated HM calibration parameter. Furthermore, these new calibration parameters are also variable in time, changing day by day for all days of the year. This approach goes a step further than the method of Aguilar and Polo (2011) which derived one new calibration parameter for the dry and one for the wet season of the year. An evaluation of the final gridded product is carried out by assessing different error metrics at grid points next to weather stations where PM ET0 is available, and also by comparing the ET0 fields with those of the operational ET0 estimates based on INCA (Integrated Nowcasting through Comprehensive Analysis, Haiden et al., 2011), the nowcasting system of the Austrian weather service.

The presented data set aims at bridging the best of two worlds by (i) using a method for estimating ET0 that is calibrated to the standard algorithm as defined by the FAO and
Table 1. Location, altitude and setting of the 42 meteorological stations used for calibration.

\begin{tabular}{|c|c|c|c|c|c|}
\hline & Station & Long $\left(^{\circ}\right)$ & Lat $\left({ }^{\circ}\right)$ & Alt (m) & Setting \\
\hline 1 & Aflenz & 15.24 & 47.55 & 783 & Mountainous \\
\hline 2 & Alberschwende & 9.85 & 47.46 & 715 & Mountainous \\
\hline 3 & Arriach & 13.85 & 46.73 & 870 & Mountainous \\
\hline 4 & Bregenz & 9.75 & 47.50 & 424 & Lakeside \\
\hline 5 & Dornbirn & 9.73 & 47.43 & 407 & Valley \\
\hline 6 & Feldkirchen & 14.10 & 46.72 & 546 & Valley \\
\hline 7 & Feuerkogel & 13.72 & 47.82 & 1618 & Summit \\
\hline 8 & Fischbach & 15.64 & 47.44 & 1034 & Mountainous \\
\hline 9 & Galzig & 10.23 & 47.13 & 2084 & Alpine \\
\hline 10 & Graz Universitaet & 15.45 & 47.08 & 366 & City \\
\hline 11 & Grossenzersdorf & 16.56 & 48.20 & 154 & Lowland \\
\hline 12 & Gumpoldskirchen & 16.28 & 48.04 & 219 & Lowland \\
\hline 13 & Irdning Gumpenstein & 14.10 & 47.50 & 702 & Valley \\
\hline 14 & Ischgl Idalpe & 10.32 & 46.98 & 2323 & Alpine \\
\hline 15 & Jenbach & 11.76 & 47.39 & 530 & Valley \\
\hline 16 & Kanzelhoehe & 13.90 & 46.68 & 1520 & Summit \\
\hline 17 & Krems & 15.62 & 48.42 & 203 & Lowland \\
\hline 18 & Kremsmünster & 14.13 & 48.06 & 382 & Lowland \\
\hline 19 & Langenlois & 15.70 & 48.47 & 207 & Lowland \\
\hline 20 & Lilienfeld Tarschberg & 15.59 & 48.03 & 696 & Mountainous \\
\hline 21 & Lofereralm & 12.65 & 47.60 & 1624 & Alpine \\
\hline 22 & Lunz am See & 15.07 & 47.85 & 612 & Valley \\
\hline 23 & Lutzmannsburg & 16.65 & 47.47 & 201 & Lowland \\
\hline 24 & Mariapfarr & 13.75 & 47.15 & 1153 & Mountainous \\
\hline 25 & Mariazell & 15.30 & 47.79 & 864 & Mountainous \\
\hline 26 & Neumarkt & 14.42 & 47.07 & 869 & Mountainous \\
\hline 27 & Patscherkofel & 11.46 & 47.21 & 2247 & Summit \\
\hline 28 & Poertschach & 14.17 & 46.63 & 450 & Lakeside \\
\hline 29 & Retz & 15.94 & 48.76 & 320 & Lowland \\
\hline 30 & Reutte & 10.72 & 47.49 & 842 & Valley \\
\hline 31 & $\begin{array}{l}\text { Rudolfshuette- } \\
\text { Alpinzentrum }\end{array}$ & 12.63 & 47.13 & 2304 & Alpine \\
\hline 32 & Schaerding & 13.43 & 48.46 & 307 & Lowland \\
\hline 33 & Schmittenhoehe & 12.74 & 47.33 & 1973 & Alpine \\
\hline 34 & Sonnblick & 15.96 & 47.05 & 3109 & Summit \\
\hline 35 & Spittal Drau & 13.49 & 46.79 & 542 & Valley \\
\hline 36 & Villacheralpe & 13.68 & 46.60 & 2156 & Summit \\
\hline 37 & Virgen & 12.46 & 47.00 & 1212 & Valley \\
\hline 38 & Weissensee Gatschach & 13.29 & 46.72 & 945 & Lakeside \\
\hline 39 & Wien Donaufeld & 16.43 & 48.26 & 161 & City \\
\hline 40 & Wien Hohewarte & 16.36 & 48.25 & 198 & City \\
\hline 41 & Wien Unterlaa & 16.42 & 48.12 & 201 & City \\
\hline 42 & Wolfsegg & 13.67 & 48.11 & 638 & Lowland \\
\hline
\end{tabular}

(ii) being applicable to a comprehensive, long-term forcing data set, on a high temporal and spatial resolution.

\section{Forcing data}

The ET0 calculations are based on a high-resolution gridded data set of daily minimum and maximum temperatures calculated for the Austrian domain (SPARTACUS, see Hiebl and Frei, 2016), whereas the actual data stretch beyond Austria to entirely cover catchments close to the border. SPARTACUS is an operational, daily-updated data set starting in 1961. For the ET0 fields, the SPARTACUS temperature forcing is used for the period 1961-2013. The interpolation algorithm is tailored to complex, mountainous terrain with spatially complex temperature distributions. SPARTACUS also aims at ensuring temporal consistency through a fixed station network 


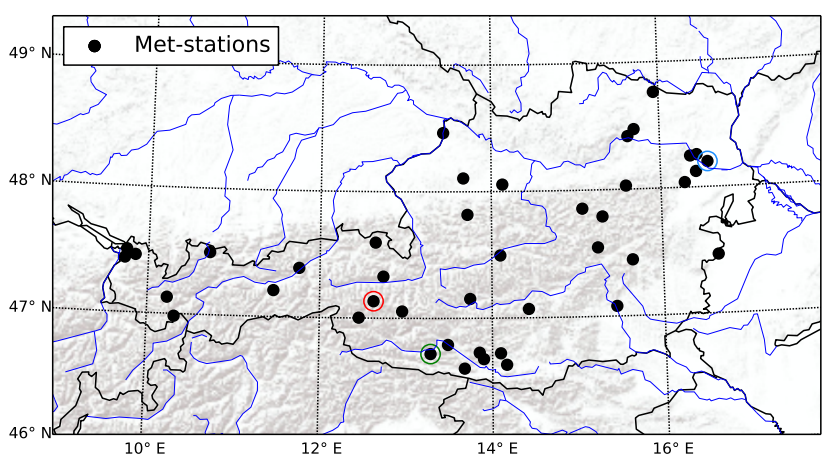

Figure 1. Location of the meteorological stations used for calibration; coloured circles around points indicate stations that are exemplary; displayed in other plots: Grossenzersdorf (blue), Weissensee Gatschach (green) and Rudolfshuette-Alpinzentrum (red).

over the full time period, providing robust trend estimations in space. SPARTACUS uses the SRTM (Shuttle Radar Topography Mission, Farr and Kobrick, 2000) version 2 Digital Elevation Model (DEM). The SRTM DEM is also applied in the present study.

SPARTACUS provides the input data for calculating ET0 following the HM (Hargreaves and Samani, 1982; Hargreaves and Allen, 2003). However, a recalibration of HM is necessary to avoid considerable estimation errors. This is carried out in a station-wise assessment. Data of 42 meteorological stations (provided by the Austrian weather service ZAMG) are used to calibrate the HM to PM on a monthly basis. Figure 1 shows the location of these stations, which are spread homogeneously over Austria and cover different elevations and environmental settings (Table 1). Data of daily global radiation, wind speed, humidity, maximum and minimum temperatures for the period 2004-2013 are used to calculate ET0 simultaneously with HM and PM.

\section{Methods}

Numerous methods exist for the estimation of ET0, which is defined as the maximum moisture loss from a standardised, vegetated surface, determined by the meteorological forcing (Shelton, 2009). These methods can roughly be classified as temperature-based and radiation-based estimates $(\mathrm{Xu}$ and Singh, 2000, 2001; Bormann, 2011). Following the recommendations of the FAO (Allen et al., 1998) the radiationbased PM provides most realistic results and generally outperforms temperature-based methods. The overall shortcoming of the PM is the data-intense calculation algorithm which requires daily values of net radiation, wind speed, humidity, maximum and minimum temperatures. Data coverage for these variables is usually rather sparse, particularly if gridded data are required. ET0 following the PM is calculated as dis- played in Eq. (1):

$$
E_{T 0_{-} p}=\frac{0.408 \Delta\left(R_{\mathrm{N}}-G\right)+\gamma \frac{900}{T+273} u_{2}\left(e_{\mathrm{S}}-e_{\mathrm{a}}\right)}{\Delta+\gamma\left(1+0.34 u_{2}\right)},
$$

where ET0_p is the reference evapotranspiration $\left(\mathrm{mm} \mathrm{day}^{-1}\right), R_{\mathrm{N}}$ is the net radiation at the crop surface $\left(\mathrm{MJ} \mathrm{m}^{-2} \mathrm{day}^{-1}\right), G$ is the soil heat flux density $\left(\mathrm{MJ} \mathrm{m}^{-2} \mathrm{day}^{-1}\right), T$ is the mean air temperature at $2 \mathrm{~m}$ height $\left({ }^{\circ} \mathrm{C}\right), u_{2}$ is the wind speed at $2 \mathrm{~m}$ height $\left(\mathrm{m} \mathrm{s}^{-1}\right)$, $e_{\mathrm{s}}$ is the saturation vapour pressure $(\mathrm{kPa}), e_{\mathrm{a}}$ is the actual vapour pressure $(\mathrm{kPa})$; giving the vapour pressure deficit by subtracting $e_{\mathrm{a}}$ from $e_{\mathrm{s}} ; \Delta$ is the slope of the vapour pressure curve $\left(\mathrm{kPa}^{\circ} \mathrm{C}^{-1}\right)$ and $\gamma$ is the psychrometric constant $\left(\mathrm{kPa}^{\circ} \mathrm{C}^{-1}\right)$. Given the time resolution of 1 day, the soil heat flux term is set to 0 . The calculation of the other individual terms of Eq. (1) is described in Allen et al. (1998). It should be mentioned, that the original PM equation contains a "surface resistance" term, expressing the response of different vegetation types, which is set constant for FAO PM, since it uses a standardised vegetated surface.

In contrast to the radiation-based PM, the HM is based on daily minimum and maximum temperatures $\left(T_{\min }, T_{\max }\right)$. Hargreaves (1975) stated from regression analysis between meteorological variables and measured ET0 that temperature multiplied by surface global radiation is able to explain $94 \%$ of the variance of ET0 for a 5-day period (see Hargreaves and Allen, 2003). Furthermore, wind and relative humidity explained only 10 and $9 \%$, respectively. Additional investigations by Hargreaves led to an assessment of surface radiation which can be explained by extra-terrestrial radiation at the top of the atmosphere and the diurnal temperature range as an indicator for the percentage of possible sunshine hours. The final form of the Hargreaves equation is given by:

$E_{T 0 \_h}=C\left(T_{\text {mean }}+17.78\right)\left(T_{\max }-T_{\min }\right)^{0.5} R_{\mathrm{a}}$,

where ET0_h is the reference evapotranspiration $\left(\mathrm{mm} \mathrm{day}^{-1}\right), T_{\text {mean }}, T_{\max }$ and $T_{\min }$ are the daily mean, maximum and minimum air temperatures $\left({ }^{\circ} \mathrm{C}\right)$, respectively, and $R_{\mathrm{a}}$ is the water equivalent of the extra-terrestrial radiation at the top of the atmosphere $\left(\mathrm{mm} \mathrm{day}^{-1}\right) . C$ is the calibration parameter of the HM and was set to 0.0023 in the original publication of Hargreaves et al. (1985).

Following these formulations the ET0 for all stations is calculated for the period 2004-2013.

In order to achieve a meaningful representation of ET0 by $\mathrm{HM}$, an adjustment of the calibration parameter $\left(C_{\mathrm{adj}}\right)$ of HM is necessary, with respect to ET0 derived from PM. This is carried out on an average monthly basis for every station by the following equation, as also proposed by Bautista et al. (2009):

$C_{\text {adj }}=0.0023 /\left(E_{\mathrm{H}} / E_{\mathrm{P}}\right)$,

where $C_{\text {adj }}$ represents the new calibration parameter of the $\mathrm{HM}, E_{\mathrm{H}}$ is the original ET0_h from HM, using a $C$ of 0.0023 
and $E_{\mathrm{P}}$ is the ET0_p from PM. As a result, a new set of $C$ values for every month and every station is available. An analysis on the behaviour of $C_{\text {adj }}$ in space revealed rather strong altitude dependence, particularly in the cold season. This feature enables the estimation of $C_{\text {adj }}$ in space for every grid point by using the underlying DEM of the temperature fields as a predictor.

As a first step, the monthly $C_{\text {adj }}$ values at every station are linearly interpolated to daily values to avoid step-wise changes and therefore abrupt shifts of $C_{\text {adj }}$ between months. This is carried out for a standard year with a length of 365 days. The result is a time series of daily changing values of $C_{\text {adj }}$ over the course of the year, available for every station, stretching over different altitudes and therefore yielding 42 different annual time series of $C_{\text {adj }}$.

Subsequently the daily, station-wise values of $C_{\text {adj }}$ are interpolated in space. The analysis of the $C_{\text {adj-altitude rela- }}$ tionship indicated nonlinear characteristics, so a third-order polynomial fit was chosen. Using the underlying DEM of the SPARTACUS data set it is possible to determine adjusted calibration parameters for every grid point in space by this relationship. The polynomial fit is applied for every day of the daily interpolated station-wise $C_{\text {adj }}$ values, since these are changing day by day as well. The result is a gridded data set of $C_{\text {adj }}$ for the SPARTACUS domain for 365 time steps from 1 January to 31 December.

Having these gridded $C_{\text {adj }}$ values, the ET0_h.c is calculated for every grid point and day from 1961 to 2013. In the case of leap years, the $C_{\text {adj }}$ grid of 28 February is also used for 29 February. The final gridded product is termed ARET (Austrian reference evapotranspiration data set) throughout the rest of the paper.

The ARET fields are finally evaluated against station data and another ET0 product. Unfortunately, there is no longterm gridded data set of ET0 for the Austrian domain, so we used the ET0 of the nowcasting system INCA (Integrated Nowcasting through Comprehensive Analysis, Haiden et al., 2011) which yields daily fields of ETO based on PM on $1 \mathrm{kmg} 104$ grid resolution. INCA uses weather stations, remote sensing data, rainfall radar data as well as DEM information to derive nowcasting fields of several meteorological variables. INCA is operational for several years, but due to constant changes in data input quality and other improvements we chose to use only the 5-year period from 2009 to 2013.

For the skill assessment of the ARET data set we calculate mean monthly values of mean bias, root mean square error (RMSE) and relative error (RE) of those grid points in ARET as well as INCA closest to a station with PM ET0.

\section{Results}

Figure 2a shows, as an example, the daily time series of ET0 as derived by PM (ET0_p) and HM (ET0_h) in the year 2004 at the station Grossenzersdorf. The differences between those two are obvious as ET0_p shows clearly higher variability, with ET0_h underestimating the upward peaks in the cold season and downward peaks in the warm season. This feature is more noticeable in Fig. 2b, which shows the monthly averages over all stations, indicating the spread among all 42 stations. Here, an underestimation of the ET0_h compared to ET0_p from October to April is counteracted by an overestimation between May and September. On the other hand, ET0_p shows higher spread among stations compared to ET0_h except for November to January.

Figure 4 shows the adjusted $C$ values for three exemplary stations. $C_{\mathrm{adj}}$ is generally higher in winter and autumn compared to the original value indicated by the dashed line at 0.0023 . It is also obvious that at station Grossenzersdorf the original value is matching rather well to the $C_{\text {adj }}$ from April to October; in the other months the adjusted values are clearly higher. On the contrary, at station Weissensee Gatschach $C_{\text {adj }}$ is lower than 0.0023 except for the months from November to February. At station Rudolfshuette-Alpinzentrum the adjusted values are above the original ones all year round, reaching the highest values in wintertime of about 0.007 . These results clearly underpin the necessity for a recalibration of $C$ in order to receive sound ET0 from temperature observations.

For simplicity, for a first assessment the monthly values of $C_{\text {adj }}$ were used for all days of the month; no temporal interpolation was conducted. As a result, the monthly mean bias is reduced to zero at every station. Furthermore, the RMSE has also slightly decreased by 0.1 to $0.2 \mathrm{~mm} \mathrm{day}^{-1}$, as can be seen in Fig. 4a. The RE has also decreased, from around 45 to fewer than $35 \%$ in January, for example (cf. Fig. 4b). The improvements regarding RE in summer are lower due to the higher absolute values of ET0 in the warm season.

The complete monthly mean time series from 2004 to 2013 of ET0_p, ET0_h and ET0_h.c for three stations are shown in Fig. 5. At station Grossenzersdorf, the underestimation of ET0_h in winter is reduced as well as the overall underestimation at station Rudolfshuette-Alpinzentrum. On the other hand, the overestimation in summer at station Weissensee-Gatschach is considerably reduced with ET0_h.c. These features in combination with the information on the altitude of the given stations provide some information on more general characteristics of $C_{\text {adj }}$ and the effects of the calibration, which underpins an altitude dependence of $C_{\text {adj }}$, which is displayed in more detail in Fig. 6. It shows the monthly average $C_{\text {adj }}$ for stations which were binned to distinct classes of altitude ranging from 100 to $2300 \mathrm{~m}$ in steps of $100 \mathrm{~m}$. As already seen in Fig. 3 as an example for three stations, $C_{\text {adj }}$ is clearly higher in winter than the unadjusted value. From April to September, $C_{\text {adj }}$ is lower than 0.0023 up to altitudes of $1500 \mathrm{~m}$ a.s.l., lowest values are visible in May to August between altitudes of 400 to $1000 \mathrm{~m}$ a.s.l. Figure 7 displays the adjusted calibration parameters plotted against altitude for the monthly means of $C_{\text {adj }}$. From this fig- 

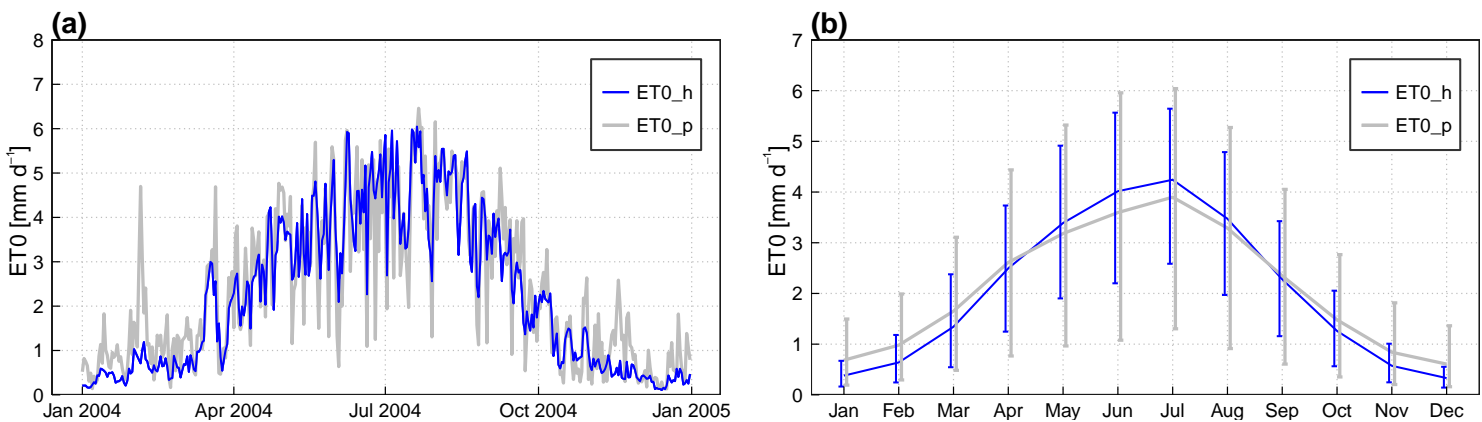

Figure 2. Daily time series of ET0 in 2004 for ET0 based on PM (ET0_p) and HM (ET0_h) at the station Grossenzersdorf (a); Monthly mean ET0 from 2004 to 2013 averaged over all stations, error bars denote the spread among all stations (b).

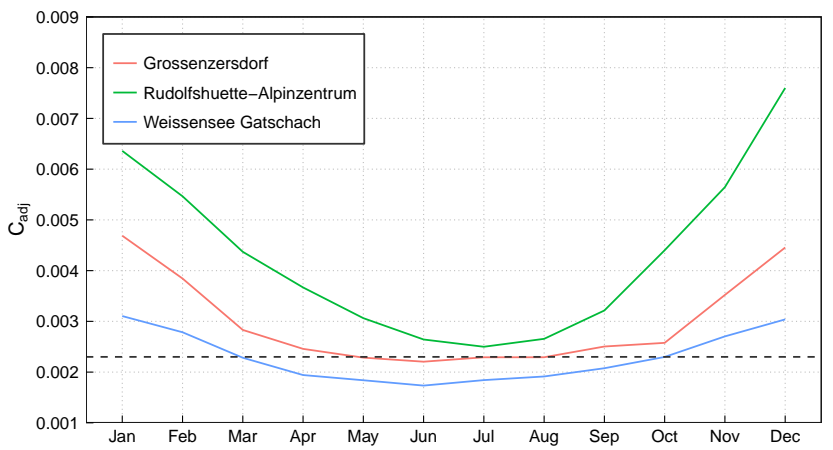

Figure 3. Monthly values of $C_{\mathrm{adj}}$ at three different stations, the dashed black lines indicates the original $C$ value of 0.0023 from Hargreaves et al. (1985).

ure it becomes clear that this relationship is not linear. $C_{\text {adj }}$ is decreasing from the very low-situated stations until altitudes between 500 and $1000 \mathrm{~m}$ a.s.l. Going further up, $C_{\text {adj }}$ increases and one could say it might be a linear increase, particularly in winter. On the other hand, looking at the summer months the station with the highest elevation (Sonnblick, $3106 \mathrm{~m}$ a.s.1.) shows somewhat lower or at least equal values of $C_{\text {adj }}$ compared to the cluster of stations between 2000 and 2400 m.a.sl. This feature indicates that the relationship above $1000 \mathrm{~m}$ a.s.l. might not be linear. Taking all these characteristics into account, a higher order polynomial fit was chosen to describe the $C_{\text {adj-altitude relation. }}$

The results of the spatial interpolation of $C_{\mathrm{adj}}$ are displayed in Fig. 8, where two examples of $C_{\text {adj }}$ distribution in space are displayed: on 1 January (a), and 1 July (b). Particularly in January, the altitude dependence of the calibration parameter is clearly standing out, showing rather high values of $C_{\text {adj }}$ in the mountainous areas. In contrast to winter, the spatial variations in summer are smaller, only some central Alpine areas between 1000 and $3000 \mathrm{~m}$ a.s.l. are appearing in somewhat different shading than the surrounding low lands.

The climatological mean (1961-2013) of the final ARET fields is displayed in Fig. 9a. Lowest daily mean values of below $1.5 \mathrm{~mm} \mathrm{day}^{-1}$ are apparent on the highest moun- tain ridges of the main Alpine crest. The highest values of $2.4 \mathrm{~mm} \mathrm{day}^{-1}$ and above are found in the eastern and southern lowlands. Other spatial features are visible as well, for example, higher ET0 in the valleys in the far western part of Austria. This higher ET0 is driven by the longer sunshine hours in these areas, which are also known as "inner alpine dry valleys", because rainfall approaching from the west is often screened by the mountain chains in the northwest. In the ET0 estimate, this feature of less cloud cover and therefore longer sunshine durations is reflected in the higher diurnal temperature range (DTR), yielding larger values in that particular area. A similar characteristic is apparent in the very south of Austria. Here ET0 is higher as well, compared to topographically similar regions on the northern rim of the Alps. This is also connected to the longer sunshine hours which indirectly enhance ET0 through higher DTR values.

Figure 9b shows the ET0 field of 8 August 2013. For the first time on that particular day, temperatures reached above $40^{\circ} \mathrm{C}$ in Austria at some stations in the east and south. Values of ET0 are particularly high, reaching up to $7 \mathrm{~mm} \mathrm{day}^{-1}$ in some areas in the southeast. That day was also characterized by an approaching cold front, which brought rain, dropping temperatures and overcast conditions from the west. These conditions were featured as well in the ET0 field, showing a considerable gradient from west to east, with almost zero ET0 at the headwaters of the Inn River in the far southwest of the domain. Furthermore, the implications of overcast conditions in the west with lower altitudinal gradients of ET0 compared to the east with sunny conditions and distinct gradients along elevation are visible.

July, the month with the highest absolute values of ET0, shows considerable variations in the last 53 years. As an example, the mean anomaly of ET0 in July of 1983 with respect to the July mean of 1961-2013 is displayed in Fig. 10a. This month was characterized by a considerable heat wave and mean temperature anomalies of $+3.5^{\circ} \mathrm{C}$ which also affected ET0. The absolute anomaly of ET0 reaches above $1 \mathrm{~mm} \mathrm{day}^{-1}$ with respect to the climatological mean in some areas. The relative anomaly is in a range between 10 to $30 \%$ (Fig. 10c). July of 1979 was rather cool instead with tempera- 

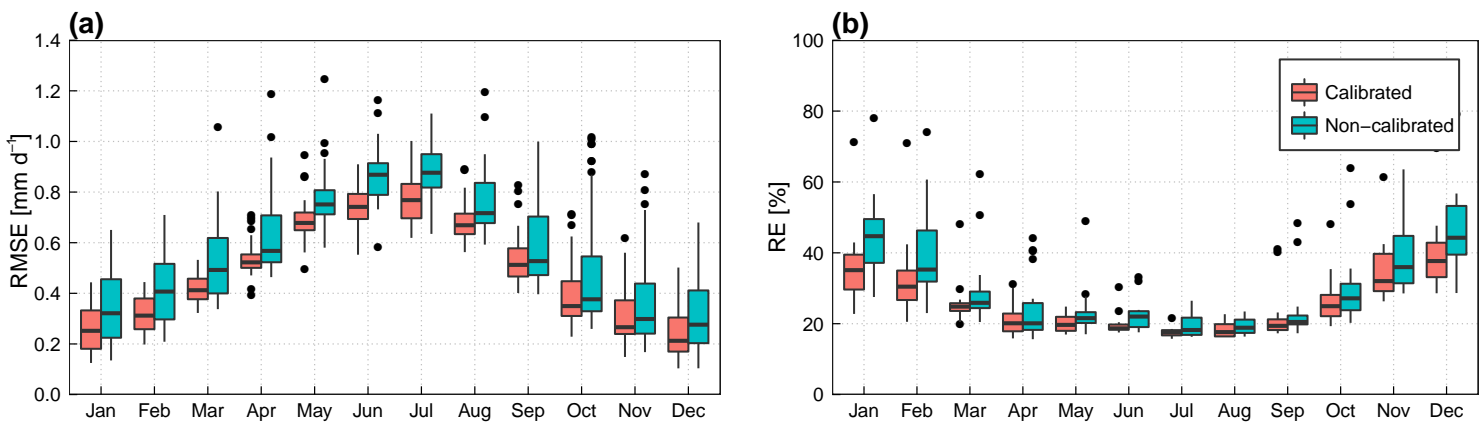

Figure 4. Monthly root mean square error (a) and monthly relative error (b) between daily ET0_p and ET0_h (black) and ET0_p and ET0_h.c (red).
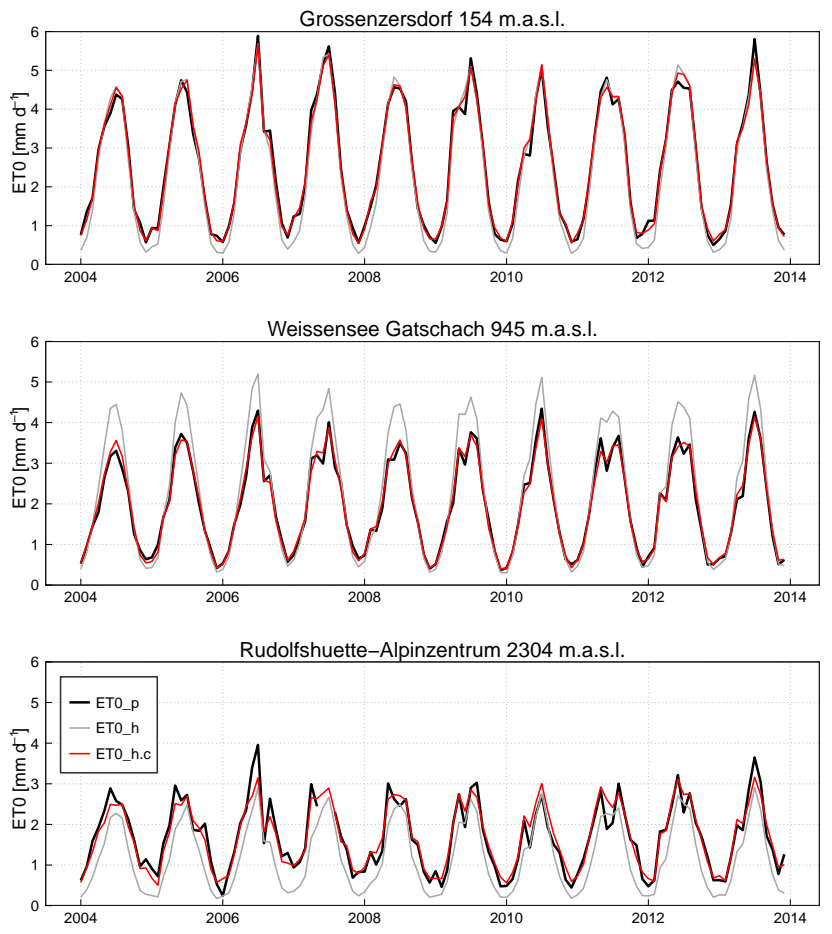

Figure 5. Monthly ET0 sums derived from ET0_p, ET0_h and ET0_h.c for three stations located at different altitudes.

tures $1.5^{\circ} \mathrm{C}$ below the climatological mean and accompanied by a strong negative anomaly in sunshine duration, particularly in the areas north of the main Alpine crest. These characteristics implicated a distinctly negative anomaly of ET0 in this particular month (Fig. 10b). The absolute anomaly stretches between 0 and more than $-1 \mathrm{~mm} \mathrm{day}^{-1}$, which is equivalent to a relative anomaly of 0 to $-30 \%$ (Fig. 10d). The negative signal is stronger in the areas north of the Alpine crest, zero anomalies are found in some areas in the south.

In Fig. 11 the overall benefits of the recalibration of the HM are revealed. It shows the mean ET0 in July 2012, a month accompanied by a considerable heat wave at the

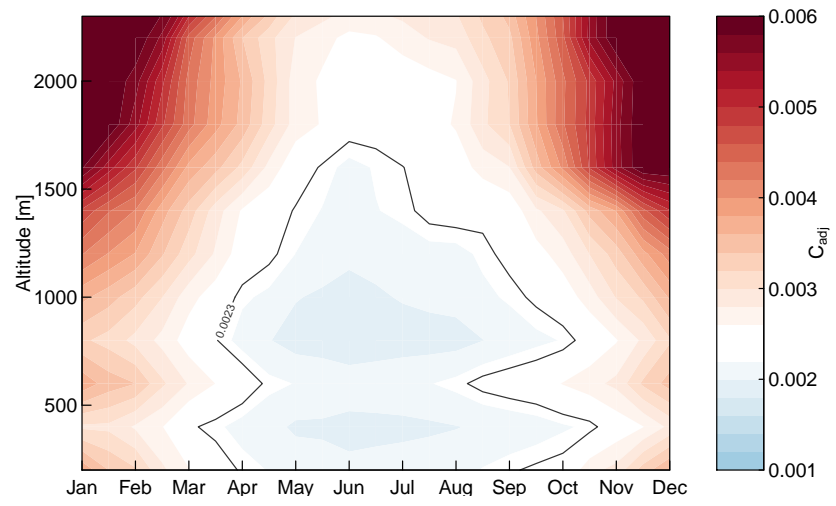

Figure 6. Monthly variations of $C_{\text {adj }}$ with respect to altitude; the black contour line defines the original Hargreaves calibration parameter $C$ value of 0.0023 ; stations are binned to classes of altitude from 100 to 2300 m every $100 \mathrm{~m}$; white areas denote classes of altitude with no station available.

beginning and an overall temperature anomaly of around $+2{ }^{\circ} \mathrm{C}$. In Fig. $11 \mathrm{~b}$, the ET0 field of the original HM formulation without calibration is shown, and Fig. 11a displays the results with recalibration as described in this study. Overall, the gradient along elevation of ET0 is larger in the noncalibrated field. Particularly in this time of the year with large absolute values, the recalibration has a considerable impact, although $C_{\text {adj }}$ in July is relatively small compared to winter. As shown before (cf. Fig. 3), the ET0 estimation using the original $C$ is good for July in the very lowlands, since biases tend to be rather small. However, going to higher elevations, the overestimation of the original HM is rather pronounced. Mean biases reach $+1 \mathrm{~mm} \mathrm{day}^{-1}$ or $+30 \%$ over large parts of the domain. This signal switches to negative biases of $-0.5 \mathrm{~mm} \mathrm{day}^{-1}(-25 \%)$ above $1500 \mathrm{~m}$ a.s.l.

The overall performance of ARET compared to the station-wise PM estimates is displayed in Fig. 12. Figure 12a shows the monthly bias of the original HM ET0 and the calibrated ET0 of the nearest grid point. The bias is clearly reduced in nearly all months. However, in April, as the only exception, the bias of the calibrated grid point values is larger 


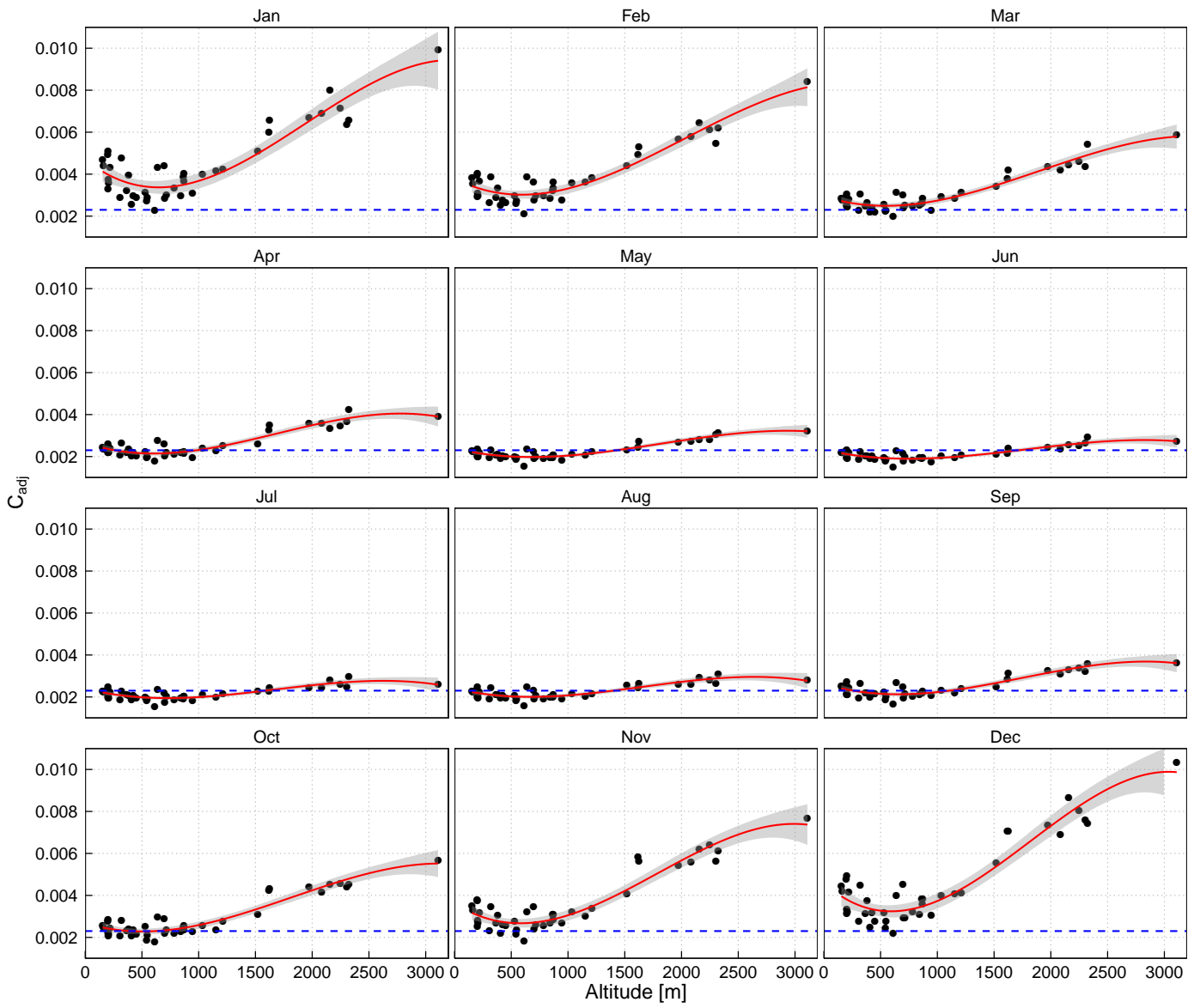

Figure 7. Station-wise monthly third-order polynomial fit of the Hargreaves calibration parameter $C_{\text {adj }}$ against altitude; the blue dotted line indicates the original $C$ value of 0.0023 .

(a)

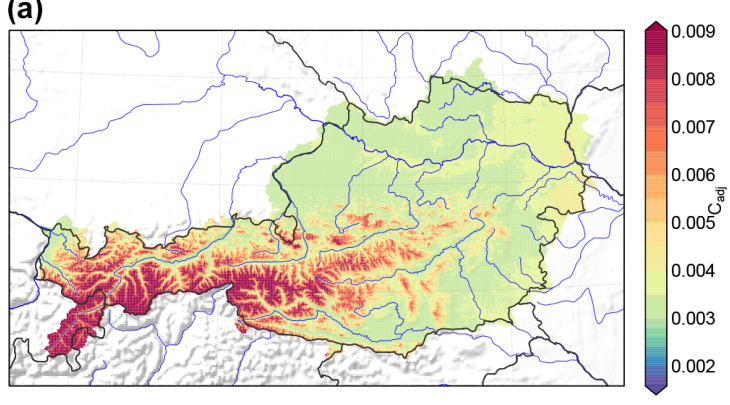

(b)

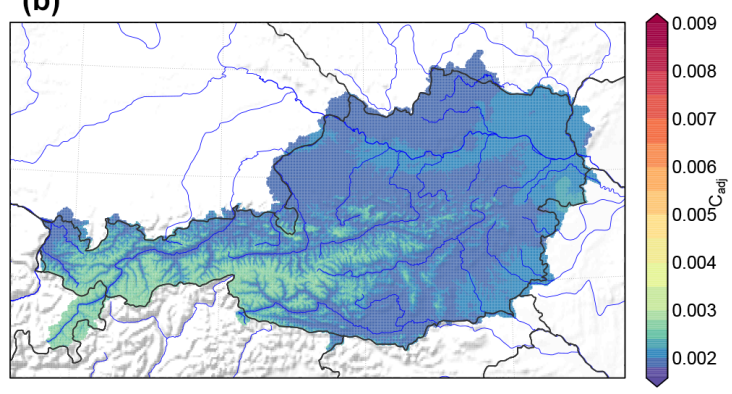

Figure 8. Spatially interpolated $C_{\text {adj }}$ values for 1 January (a) and 1 July (b).

than the bias of the original estimation. The biases concerning different levels of altitude are reduced as well, as can be seen in Fig. 12b, which shows the biases in July, and Fig. 12c displaying the biases in January.

A comparison between ARET and INCA ET0 and stationbased PM ET0 is given in Fig. 13, showing ET0 on two different days in summer 2013. The first example (Fig. 13a and b) is 4 June 2013 , a day with mostly overcast conditions, lower than average temperatures of between 7 to $12^{\circ} \mathrm{C}$ and high relative humidity (it was the time after a big flood event in northern Austria). ARET is clearly overestimating ET0 by a median difference of $+1 \mathrm{~mm} \mathrm{day}^{-1}$ across all stations, as shown by the boxplot in Fig. 13c. INCA has a median difference of nearly zero, although the spread is larger than in ARET. Another example is 23 July 2013 (Fig. 13d and e) which characterized by temperatures ranging between 20 in the west and $29^{\circ} \mathrm{C}$ in the east, accompanied by some rainfall in the west and south. ET0 in both ARET and INCA 

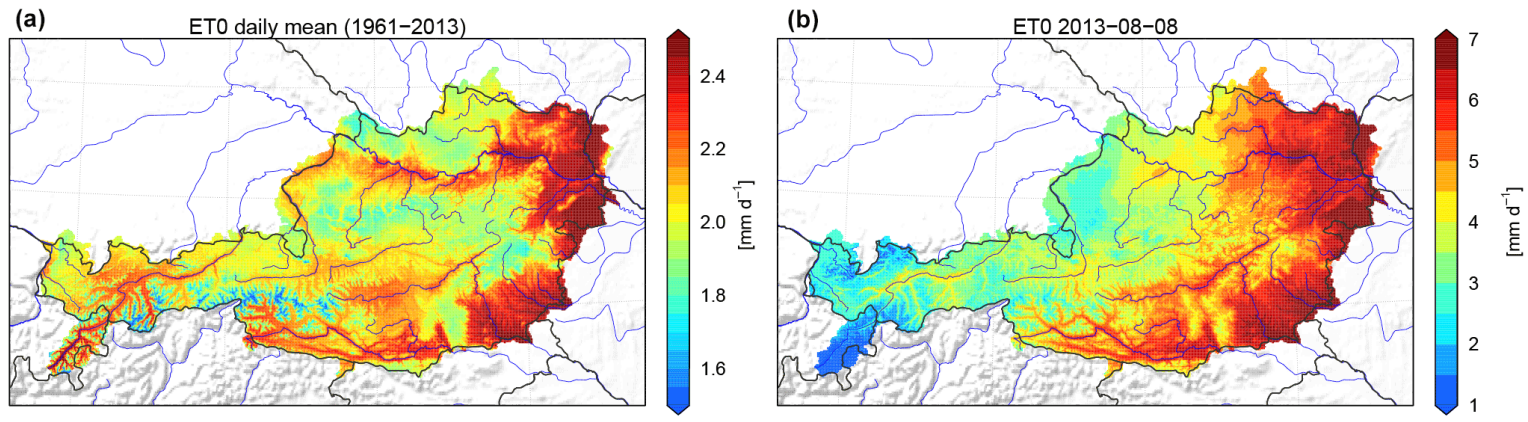

Figure 9. Climatological daily mean ET0 from 1961-2013 (a); example of a daily field of ET0 on 8 August 2013 (b).

(a)

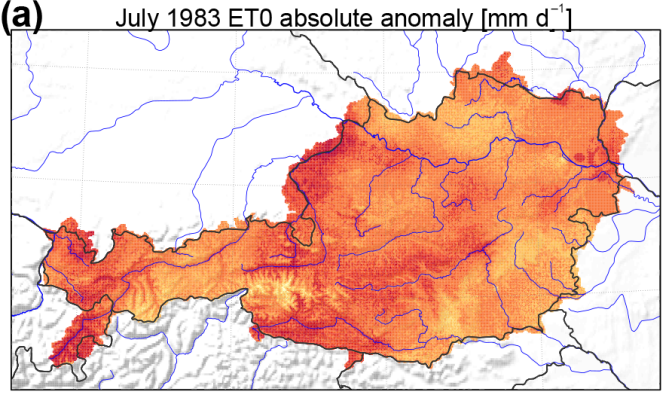

(C) July 1983 ETO relative anomaly [\%]

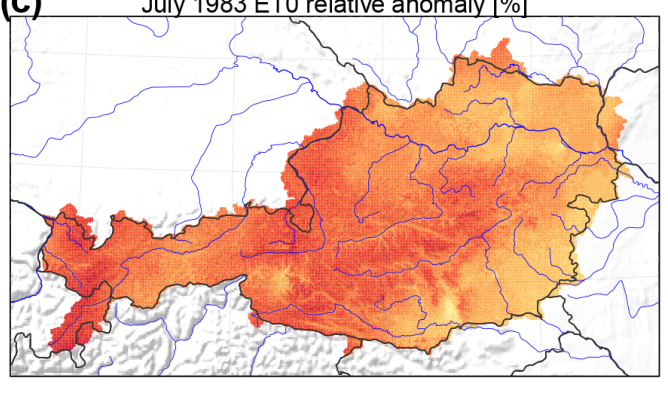

(b)

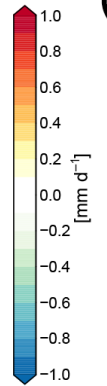

$\mathrm{A}^{30} \quad(\mathrm{~d})$

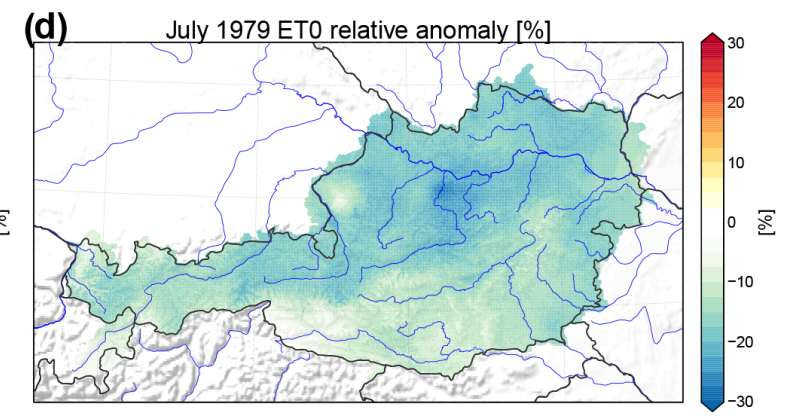

Figure 10. Upper panel: absolute anomalies of ET0 sum in July 1983 (a) and July 1979 (b) with respect to the climatological mean in July from 1961-2013; lower panel: corresponding relative anomaly (c, d).

range between 3 and $6 \mathrm{mmday}^{-1}$, although INCA shows a general overestimation with a median difference around $+0.5 \mathrm{~mm} \mathrm{day}^{-1}$ (Fig. 13f). On the other hand, median differences of ARET compared to stations are around zero.

However, comparing error characteristics in ARET and INCA against station data (Table 2) for the period 20092013 reveals only minor differences. The mean bias all year round is lower in INCA $\left(0.03 \mathrm{~mm} \mathrm{day}^{-1}\right)$ compared to ARET $\left(0.12 \mathrm{~mm} \mathrm{day}^{-1}\right)$. Considering monthly mean values, the spread is rather similar spanning -0.30 to 0.66 in INCA and -0.17 to $0.80 \mathrm{mmday}^{-1}$ in ARET. The highest monthly mean values are in both data sets found in April (ARET: $0.80 \mathrm{~mm} \mathrm{day}^{-1}$, INCA: $0.66 \mathrm{~mm} \mathrm{day}^{-1}$ ) and May (ARET: $0.79 \mathrm{~mm} \mathrm{day}^{-1}$, INCA: $0.51 \mathrm{~mm} \mathrm{day}^{-1}$ ). The RMSE is slightly lower in ARET, reaching maximum values in June of 1.42 , compared to INCA with $1.80 \mathrm{~mm} \mathrm{day}^{-1}$. The overall mean RMSE is 0.89 in ARET and $1.05 \mathrm{~mm}_{\text {day }}{ }^{-1}$ in
INCA. Concerning the RE, the characteristics are similar to the bias and the RMSE, with only minor differences between ARET and INCA. The RE in ARET ranges between +35 (April) and $-15 \%$ (November), and in INCA these are rather similar, spanning +25 (February) and $-18 \%$ (November).

\section{Discussion}

By comparing the characteristics of ET0 based on HM and PM on a daily time step, it became clear that a recalibration of $C$ within the formulation of Hargreaves follows distinct patterns. The values of $C_{\text {adj }}$ show marked variations in space and time (over the course of the year). It turned out, that a monthly recalibration of $C$ reveals an annual cycle of $C_{\text {adj }}$, with $C_{\text {adj }}$ being close to the original value of 0.0023 in the warm season (April-October) and low elevations. Going to 

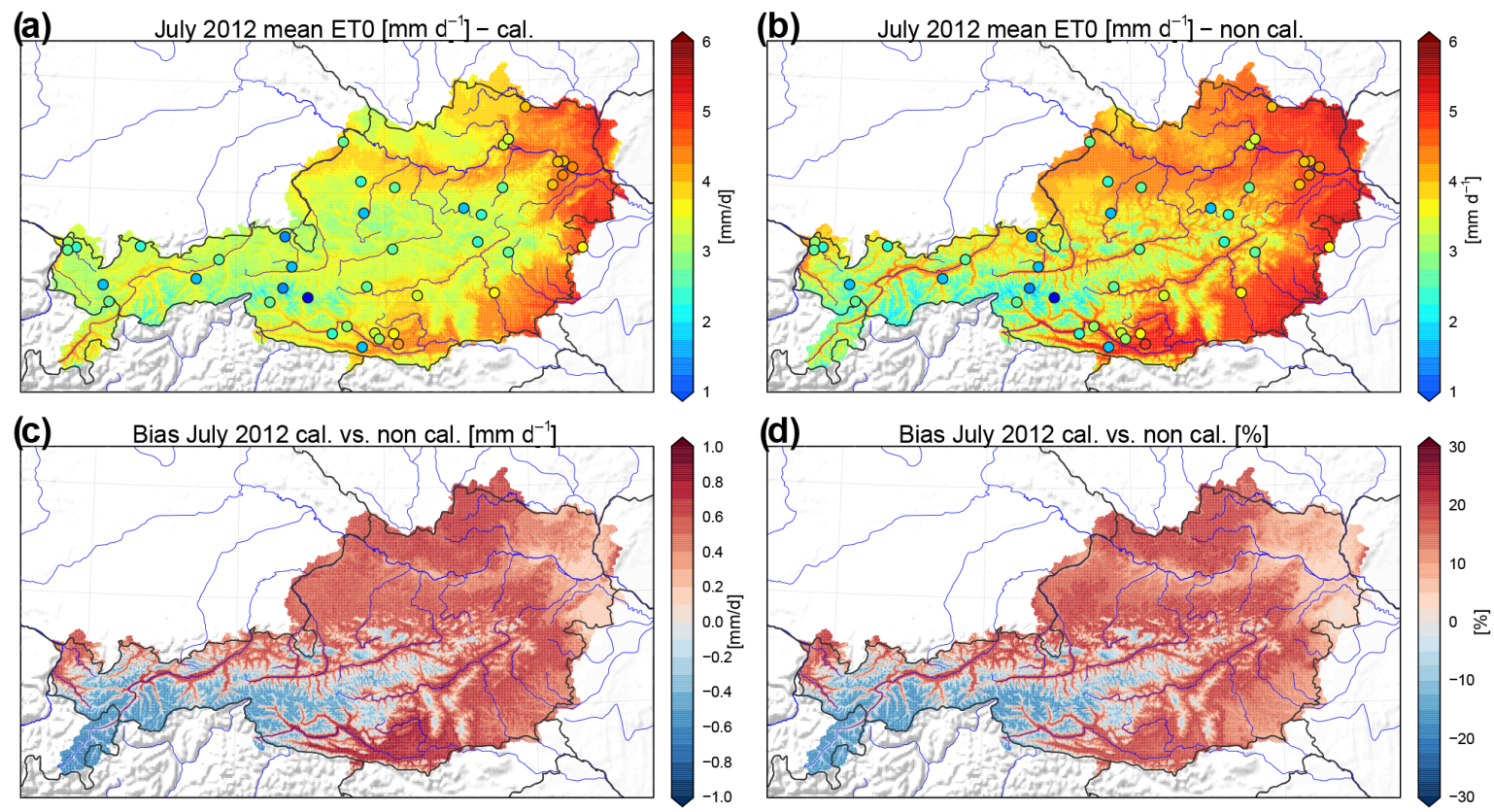

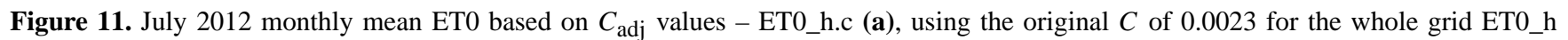
(b) and the corresponding absolute (c) and relative bias (d); the dots in (a) and (b) denote the PM ET0 at the stations.

Table 2. Error characteristics of ARET and INCA against station data.

\begin{tabular}{lrr|rr|rr}
\hline & \multicolumn{2}{c}{${\text { Bias }\left[\mathrm{mm} \mathrm{day}^{-1}\right]}^{2}$ RMSE $\left[\mathrm{mm} \mathrm{day}^{-1}\right.$ ] } & \multicolumn{2}{c}{ RE [\%] } \\
\cline { 2 - 7 } & ARET & INCA & ARET & INCA & ARET & INCA \\
\hline January & -0.01 & -0.05 & 0.29 & 0.34 & 1 & -7 \\
February & -0.17 & -0.30 & 0.60 & 0.65 & -12 & -25 \\
March & 0.04 & -0.23 & 0.84 & 0.89 & 4 & -14 \\
April & 0.80 & 0.66 & 1.34 & 1.59 & 35 & 28 \\
May & 0.79 & 0.51 & 1.38 & 1.58 & 29 & 19 \\
June & 0.19 & -0.24 & 1.42 & 1.80 & 6 & -8 \\
July & 0.39 & 0.31 & 1.29 & 1.58 & 12 & 9 \\
August & -0.09 & -0.01 & 1.16 & 1.42 & -1 & 1 \\
September & -0.14 & -0.10 & 0.96 & 1.11 & -6 & -4 \\
October & -0.15 & -0.06 & 0.57 & 0.69 & -8 & -3 \\
November & -0.03 & 0.01 & 0.43 & 0.54 & 2 & 5 \\
December & -0.16 & -0.18 & 0.39 & 0.43 & -15 & -18 \\
Year & 0.12 & 0.03 & 0.89 & 1.05 & 4 & -1 \\
\hline
\end{tabular}

higher elevations, $C_{\text {adj }}$ decreases until roughly $1000 \mathrm{~m}$ a.s.l. Reaching altitudes above $1700 \mathrm{~m}$ a.s.l., $C_{\text {adj }}$ generally has a higher value than Hargreaves' original value, particularly during the cold season (November-March). This altitude dependency of the calibration parameter in HM is mentioned in Samani (2000), but the authors also claimed that this relationship may be affected by different latitudes. Aguila and Polo (2011) also found that the original HM using a $C$ of 0.0023 underestimates ET0 at higher elevations and defined a value of 0.0038 at an elevation of $2500 \mathrm{~m}$ a.s.l. However, this altitude dependency of $C$ turned out to be more com- plex, as we are able to display, showing a distinct variation throughout the year along with elevation.

To reveal the sources of this altitude dependence of $C$, some additional analysis was done. In general, the HM utilises the diurnal temperature range (DTR, $T_{\max }$ minus $T_{\min }$ ) to mimic the amount of global radiation at the land surface. Clear sky conditions are usually associated with higher DTR. There is more heating during daytime due to large proportions of direct solar radiation, whereas at night time temperatures drop further down since the outgoing long-wave radiation is not reflected by clouds. Numerous studies investigating the relationship between DTR and radiation (Pan et al., 2013; Makowski et al., 2009; Bindi and Miglietta, 1991; Bristow and Campbell, 1984) show considerable correlations. For example, Makowski et al. (2009) reported a correlation coefficient of 0.87 of the annual means of DTR and solar radiation averaged over 31 stations across Europe.

Figure 14 shows the linear regression coefficients of the square root of DTR and global top-of-atmosphere (TOA) radiation ratio on a daily timescale at the 42 stations used in this study. The idea is to get a better understanding of the parameterization embedded in HM, which tries to assess the amount of global radiation via the DTR and the TOA radiation. The coefficients show a distinct altitudinal dependency, particularly in winter. In January, the coefficients are generally high at altitudes between 300 and $1100 \mathrm{~m}$ a.s.l. At higher elevations they are dropping considerably, getting slightly negative above $3000 \mathrm{~m}$ a.s.l. at station Sonnblick. This altitude dependency is also apparent in the transitional season (cf. Fig. 14; April and October) although not as pronounced as in 

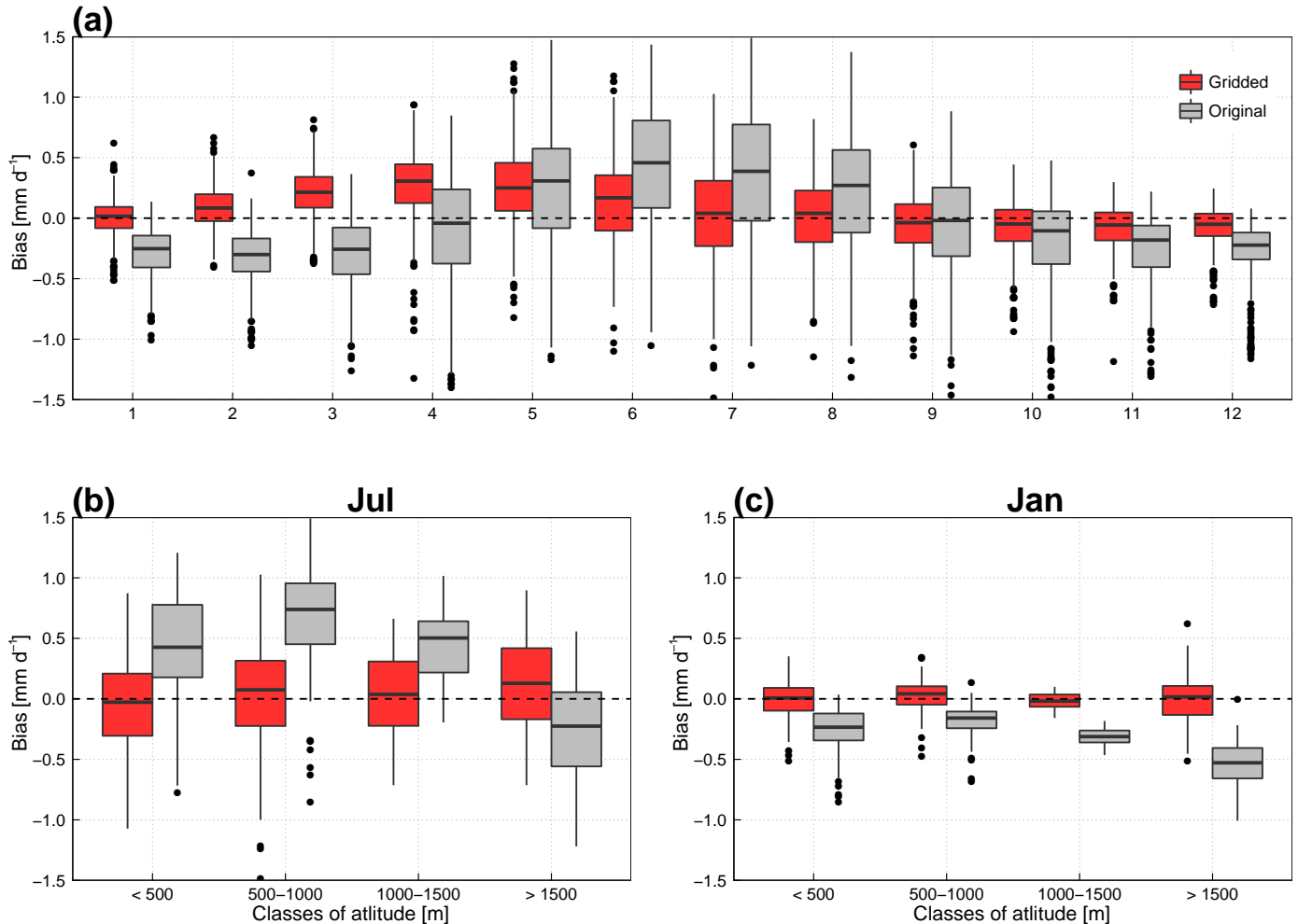

Figure 12. Boxplots of monthly mean bias of the station-wise original Hargreaves ET0 (grey) and the ARET, recalibrated ET0 (red) against PM ET0 (a); stratified by different classes of altitude in July (b) and January (c).

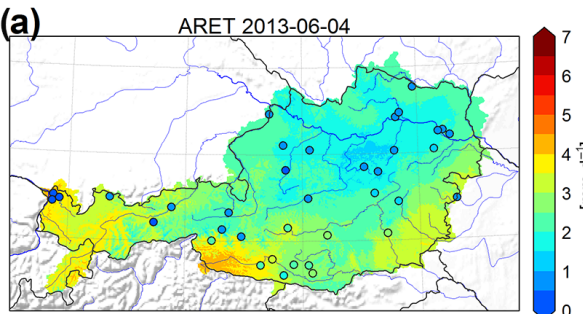

(d)

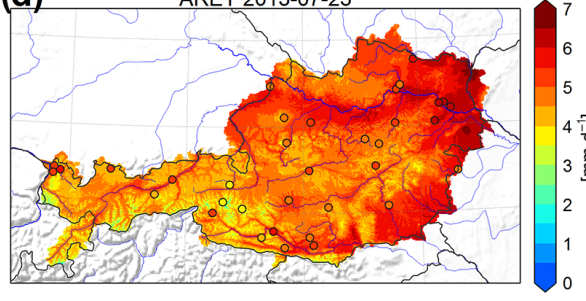

(b)

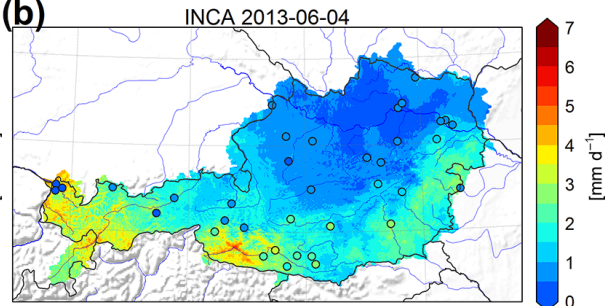

(e)

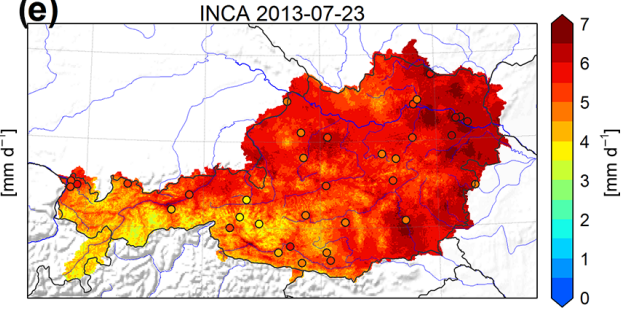

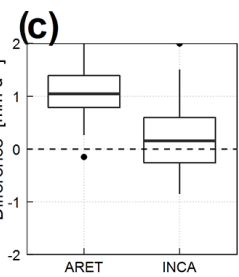

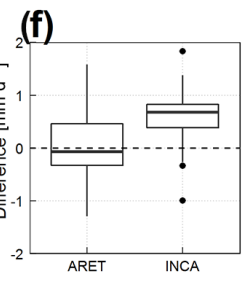

Figure 13. ET0 fields of ARET (a, d) and INCA (b, e) and station-wise PM ET0 on 4 June 2013 (cool and overcast conditions) and 23 July 2013 (warm and mostly sunny conditions) and corresponding differences at grid points closest to a station with PM ET0 of both data sets displayed as boxplots $(\mathbf{c}, \mathbf{f})$.

winter. In July, the coefficients are generally higher, roughly ranging between 0.15 and 0.30 , with no change along altitude.

The reasons for the patterns in Fig. 14 seem to be rooted in the lower atmospheric mixing ratios at the lowest stations, some of them located in or near cities, which might dampen the DTR, although clear sky conditions are apparent. At moderate altitudes between 400 and $1500 \mathrm{~m}$ a.s.l. the daily temperature amplitude is more dominantly driven by surface energy balance processes which reflect higher regression coefficients. Going further up, the proportion of the DTR which is determined by large-scale air mass changes rises, as 


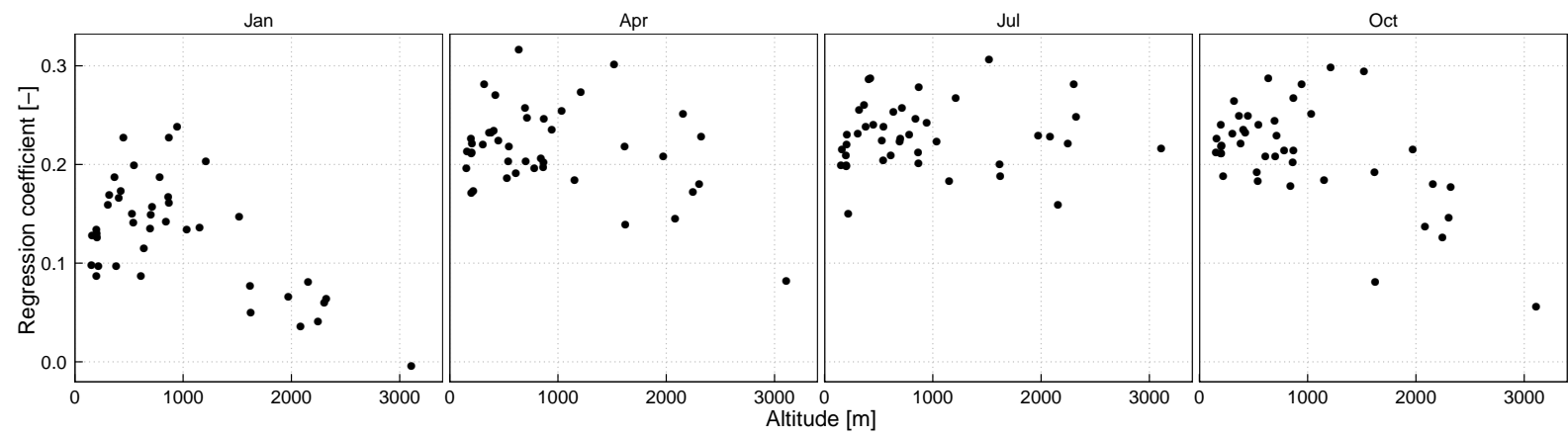

Figure 14. Station-wise linear regression coefficient of the TOA radiation to global radiation ratio against the square root of the diurnal temperature range $\left(T_{\max }-T_{\min }\right)$ against altitude represented by black dots in January, April, July and October.

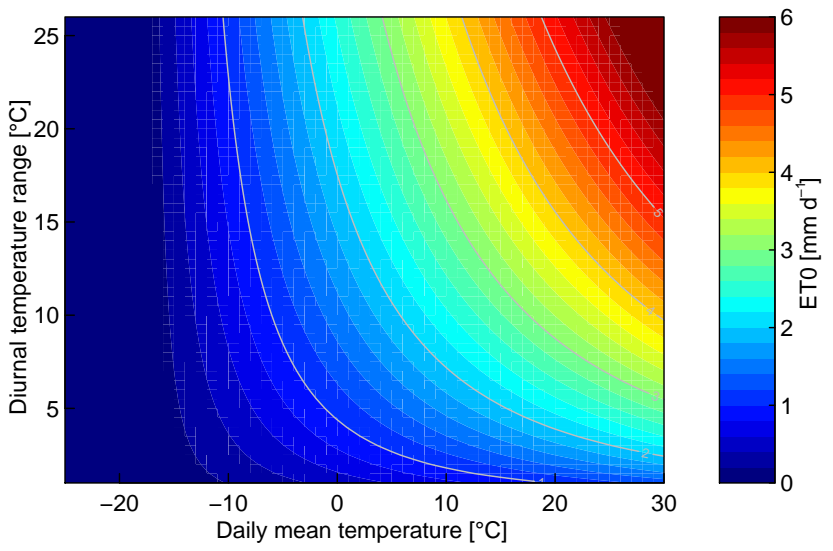

Figure 15. ET0 response to varying daily mean temperature and diurnal temperature range; ET0 values are calculated with 1 April top-of-the-atmosphere radiation and the original $C$ value of 0.0023 .

the station locations reach up above the planetary boundary layer into the free atmosphere. Thus, for any given value of cloudiness, DTR is much smaller in winter and at high elevations than in low-elevation environments where boundary layer processes are dominant. This means that for yielding realistic values of global radiation relative to TOA radiation, a much higher $C_{\text {adj }}$ value is needed to compensate.

Although these circumstances seem to be a drawback of the methodology, the overall effect is only minor. Figure 15 shows the HM ET0 in dependence of the DTR and the daily mean temperature. At low daily mean temperatures, between -10 and $+10^{\circ} \mathrm{C}$, the contour lines determining the value of ET0 are rather steep. This implies that a change in DTR has only minor effects on the ET0 outcome, whereas a change in daily mean temperature is more important.

However, the procedure of altering the coefficient $C$ also has implications on the variability of ET0 on a daily timescale. As was visible in Fig. 2a, the variability of ET0 based on HM is lower than PM. The presented recalibration has only little effect on the enhancement of variability. By scaling $C$, variability is slightly enhanced in those areas and in the time of the year where $C_{\text {adj }}$ is higher than 0.0023 . This is the case for most of the time and for widespread areas, but there are regions or altitudinal levels where the opposite is taking place. As is visible in Fig. 6, areas up to $1500 \mathrm{~m}$ a.s.l. show lower than original values of $C_{\text {adj }}$ in the summer months. There are particular areas in June between altitudes of 500 to $1000 \mathrm{~m}$ a.s.l. that show the largest deviation from the original value. In these areas variability is lower in the recalibrated version. On the other hand, the benefit of an ET0 formulation being unbiased compared to the reference of PM may overcome these shortcomings.

Evaluating both the ARET and INCA gridded ET0 estimates against station-based ET0 revealed only minor differences in bias, RMSE and RE, which underpins the strength of the proposed calibration method. However, there are situations where the deviations compared to station-based ET0 are particularly large in both the ARET and the INCA data set. As an example for overcast conditions after a considerable amount of rainfall, for a couple of days we compared ARET to INCA ET0 (cf. Fig. 13) and found that ARET clearly overestimates ET0. Under the given circumstances, ARET cannot compete with INCA, which considers, through the use of PM, information on relative humidity, which might have a strong forcing on ET0 on that particular day (information that is not available in the ARET estimate). On the other hand, on a typical sunny summer day, INCA overestimates ET0, where ARET is rather close to the station estimates. There might be some biases in the radiation analysis in INCA causing this deviation from the station data. Global Radiation is calculated based on sunshine duration estimates (blended remote sensing and station data) driving a simple radiation model (Haiden et al., 2011).

As shown in the evaluation of the ARET fields against INCA, the error characteristics are rather similar, although in INCA ET0 is calculated using PM. The calibration of HM, though very simple, yields very satisfying results of the final product. Particularly when considering Austrian topography it comes clear that using a method like HM without calibration has major impacts on the result. Using noncalibrated HM 
ET0 data for rainfall-runoff modelling, for example, would introduce large errors and uncertainties. Given the fact that gridded data of ET0 based on PM are only available for a rather short time period from the INCA system, the ARET data set provides a sound alternative for ET0 estimates on a high spatial resolution covering the last 53 years.

\section{Conclusions}

In this paper, a gridded data set of ET0 for the Austrian domain from 1961-2013 on daily time step is presented. The forcing fields for estimating ET0 are daily minimum and maximum temperatures from the SPARTACUS data set (Hiebl and Frei, 2016). These fields are used to calculate ET0 by the formulation of Hargreaves et al. (1985). The HM is calibrated to the PM equation, which is the recommended method by the FAO (Allen et al., 1998). This is done using a set of 42 meteorological stations from 2004-2013, which have full data availability for calculating ET0 by PM. The adjusted monthly calibration parameters $C_{\text {adj }}$ are interpolated in time (resulting in daily $C_{\text {adj }}$ for a standard year) and space (resulting in $C_{\text {adj }}$ for every grid point of SPARTACUS and day of year). With these gridded $C_{\text {adj }}$ the daily fields of reference evapotranspiration are calculated for the time period from 1961-2013.

This data set is highly valuable for users in the field of hydrology, agriculture, ecology (among others) as it provides ET0 in a high spatial resolution and a long time period. Data for calculating ET0 by recommended PM are usually not available for such long time spans and/or with this spatial and temporal resolution. However, the method presented in this study combined both strengths of long time series, high spatial and temporal resolution provided by the temperaturebased HM and the physical, more realistic radiation-based PM by adjusting HM.

Acknowledgements. The authors want to thank the Federal Ministry of Science, Research and Economy (Grant 1410K214014B) for financial support. We also like to thank Johann Hiebl for providing the SPARTACUS data and for fruitful discussions on the manuscript. The Austrian Weather Service (ZAMG) is acknowledged for providing the data of 42 meteorological stations. We would also like to thank two anonymous reviewers for the valuable comments which improved the manuscript substantially.

Edited by: J. Seibert

\section{References}

Aguilar, C. and Polo, M. J.: Generating reference evapotranspiration surfaces from the Hargreavesn equation at watershed scale, Hydrol. Earth Syst. Sci., 15, 2495-2508, doi:10.5194/hess-152495-2011, 2011.
Allen, R. G., Pereira, L. S., Raes, D., and Smith, M.: Crop evapotranspiration - Guidelines for computing crop water requirements, FAO Irrigation and drainage paper 56, Rome, 15 pp., 1998.

Bautista, F., Bautista, D., and Delgado-Carranza, C.: Calibrating the equations of Hargreaves and Thornthwaite to estimate the potential evapotranspiration in semi-arid and subhumid tropical climates for regional applications, Atmósfera, 22, 331-348, 2009.

Bindi, M. and Miglietta, F.: Estimating daily global radiation from air temperature and rainfall measurements, Climatic Change, 1, 117-124, 1991.

Bormann, H.: Sensitivity analysis of 18 different potential evapotranspiration models to observed climatic change at German climate stations, Climatic Change, 104, 729-753, 2011.

Bristow, K. L. and Campbell, G. S.: On the relationship between incoming solar radiation and daily maximum and minimum temperature, Agr. Forest Meteorol., 31, 159-166, 1984.

Chattopadhyay, N. and Hulme, M.: Evaporation and potential evapotranspiration in India under conditions of recent and future climate changes, Agr. Forest Meteorol. 87, 55-74, 1997.

Doorenbros, J. and Pruitt, O. W.: Crop water requirements, FAO Irrigation and Drainage Paper 24, Rome, 144 pp., 1977.

Farr, T. G. and Kobrick, M.: Shuttle Radar Topography Mission produces a wealth of data, EOS, Trans. Am. Geophys. Union, 81, 583-585, 2000.

Gavilán, P., Lorite, I. J., Tornero, S., and Berengena, J.: Regional calibration of Hargreaves equation for estimating reference ET in a semiarid environment, Agr. Water Manage., 81, 257-281, 2006.

Haiden, T., Kann, A., Wittmann, C., Pistotnik, G., Bica, B., and Gruber C.: The Integrated Nowcasting through Comprehensive Analysis (INCA) System and Its Validation over the Eastern Alpine Region, Weather Forecast., 26, 166-183, 2011.

Hargreaves, G. H.: Moisture Availability and Crop Production, Transactions of the American Society of Agricultural and Biological Engineers, 18, 980-984, 1975.

Hargreaves, G. H. and Allen, R.: History and Evaluation of Hargreaves Evapotranspiration Equation, J. Irrig. Drain E.-ASCE, 129, 53-63, 2003.

Hargreaves, G. H. and Samani, Z. A.: Estimating potential evapotranspiration, J. Irrig. Drain E.-ASCE, 108, 225-230, 1982.

Hargreaves, G. H. and Samani, Z. A.: Reference crop evapotranspiration from temperature, Appl. Eng. Agric., 1, 96-99, 1985.

Hargreaves, G. L., Hargreaves, G. H., and Riley, J. P.: Irrigation water requirements for Senegal River Basin, J. Irrig. Drain E.ASCE, 111, 265-275, 1985.

Hiebl, J. and Frei, C.: Daily temperature grids for Austria since 1961 - concept, creation and applicability, Theor. Appl. Climatol., submitted, 2016.

Lhomme, J.-P.: Towards a rational definition of potential evapotranspiration, Hydrol. Earth Sys. Sci., 1, 257-264, 1997.

McMahon, T. A., Peel, M. C., Lowe, L., Srikanthan, R., and McVicar, T. R.: Estimating actual, potential, reference crop and pan evaporation using standard meteorological data: a pragmatic synthesis, Hydrol. Earth Syst. Sci., 17, 1331-1363, doi:10.5194/hess-17-1331-2013, 2013.

McVicar, T. R., Van Niel, T. G., Li, L., Hutchinson, M. F., Mu, X.-M., and Liu, Z.-H.: Spatially distributing monthly reference 
evapotranspiration and pan evaporation considering topographic influences, J. Hydrol., 338, 196-220, 2007.

Makowski, K., Jaeger E. B., Chiacchio, M., Wild, M., Ewen, T., and Ohmura, A.: On the relationship between diurnal temperature range and surface solar radiation in Europe, J. Geophys. Res., 114, D00D07, doi:10.1029/2008JD011104, 2009.

Mancosu, N., Snyder, R., and Spano, D.: Procedures to Develop a Standardized Reference Evapotranspiration Zone Map, J. Irrig. Drain Eng., A4014004, doi:10.1061/(ASCE)IR.19434774.0000697, 2014.

Pan, T., Wu, S., Dai, E., and Liu, Y.: Estimating the daily global solar radiation spatial distribution from diurnal temperature ranges over the Tibetan Plateau in China, Applied Energy, 107, 384 393, 2013.

Pandey, V., Pandey, P. K., and Mahanta, A. P.: Calibration and performance verification of Hargreaves Samani equation in a humid region, Irrig. Drain., 63, 659-667, 2014.

Samani, Z.: Estimating Solar Radiation and Evapotranspiration Using Minimum Climatological Data (Hargreaves-Samani equation), J. Irrig. Drain E.-ASCE, 126, 265-267, 2000.

Shelton, M. L.: Hydroclimatology, Cambridge University Press, Cambridge, United Kingdom, 2009.
Tabari, H. and Talaee, P.: Local Calibration of the Hargreaves and Priestley-Taylor Equations for Estimating Reference Evapotranspiration in Arid and Cold Climates of Iran Based on the Penman-Monteith Model, J. Hydrol. Eng., 16, 837-845, 2011.

Tegos, A., Malamos, M., and Koutsoyiannis, D.: A parsimonious regional parametric evapotranspiration model based on a simplification of the Penman-Monteith formula, J. Hydrol., 524, 708714, 2015.

Todorovic, M., Karic, B., and Pereira, L. S.: Reference evapotranspiration estimate with limited weather data across a range of Mediterranean climates, J. Hydrol., 481, 166-176, 2011.

$\mathrm{Xu}, \mathrm{C} .-\mathrm{Y}$. and Chen D.: Comparison of seven models for estimation of evapotranspiration and groundwater recharge using lysimeter measurement data in Germany, Hydrol. Process., 19, 3717-3734, 2005.

$\mathrm{Xu}$, C.-Y. and Singh, V. P.: Evaluation and generalization of radiation-based equations for calculating evaporation, Hydrol. Process., 14, 339-349, 2000.

$\mathrm{Xu}$, C.-Y. and Singh, V. P.: Evaluation and generalization of temperature-based equations for calculating evaporation, Hydrol Process., 14, 339-349, 2001. 